\title{
Real-world outcomes of surgery for native mitral valve endocarditis
}

\author{
Nana Toyoda, MD, PhD, ${ }^{a}$ Shinobu Itagaki, MD, MS, ${ }^{a}$ Natalia N. Egorova, PhD,,${ }^{\mathrm{b}}$ Henry Tannous, MD, ${ }^{\mathrm{a}, \mathrm{c}}$ \\ Anelechi C. Anyanwu, MD, ${ }^{\mathrm{a}}$ Ahmed El-Eshmawi, MD, ${ }^{\mathrm{a}}$ David H. Adams, MD, ${ }^{\mathrm{a}}$ and Joanna Chikwe, MD ${ }^{\mathrm{a}, \mathrm{c}}$
}

\section{ABSTRACT}

Background: Consensus guidelines recommend repair over replacement for the surgical treatment of active native mitral valve infective endocarditis. However, contemporary practice and long-term outcome data are limited.

Methods: Multivariable Cox regression was used to compare outcomes of 1970 patients undergoing isolated primary mitral valve repair $(n=367,19 \%)$ or replacement $(\mathrm{n}=1603,81 \%)$ for active infective endocarditis between 1998 and 2010 in New York and California states. The primary outcome was long-term survival. Secondary outcomes were recurrent endocarditis and mitral reoperation. Median follow-up time was 6.6 years (range 0-12), and last follow-up date was December 31, 2015.

Results: Mitral valve repair rates increased from $10.7 \%$ to $19.4 \%$ over the study period $(P<.001)$. Patients undergoing mitral repair were younger $(55 \pm 15 \mathrm{vs}$ $57 \pm 15$ years, $P=.005)$, less likely to have congestive heart failure $(46.3 \%$ vs $57.1 \%, P<.001)$, and less likely to have staphylococcal infections $(21.3 \%$ vs $32.0 \%, P<.001)$. Twelve-year survival was $68.8 \%(95 \%$ confidence interval [CI], 62.5\%-74.3\%) after mitral repair, versus 53.5\% (95\% CI, 50.6\%-56.4\%) after replacement (adjusted hazard ratio, $0.71 ; 95 \% \mathrm{CI}, 0.57-0.88 ; P=.002$ ). Mitral repair was associated with lower rate of recurrent endocarditis at 12 years than replacement $(4.7 \%$ [95\% CI, 2.8\%-7.2\%] vs 9.5\% [95\% CI, 8.0-11.1\%]; $P=.03)$, and similar rate of reoperation $(9.1 \%$ [95\% CI, $6.2 \%-12.8 \%$ ] vs $8.6 \%$ $[95 \% \mathrm{CI}, 7.1 \%-10.4 \%] ; P=.12)$.

Conclusions: In active endocarditis, mitral valve repair is associated with better survival and lower risk of recurrent infection compared with valve replacement and should be the surgery of choice when feasible. ( $\mathrm{J}$ Thorac Cardiovasc Surg 2017;154:1906-12)

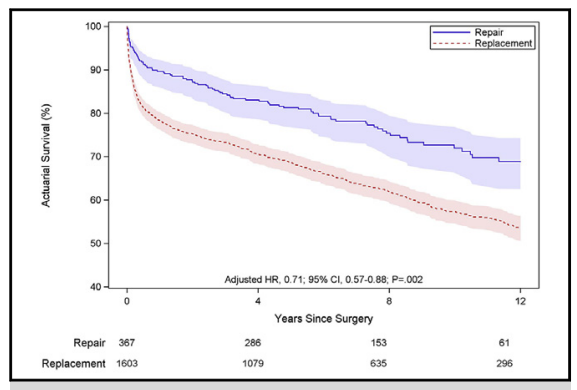

Improved survival after mitral valve repair versus replacement for active endocarditis.

\section{Central Message}

In active endocarditis, mitral valve repair is associated with better survival and lower risk of recurrent infection compared with valve replacement and should be the surgery of choice when feasible.

\section{Perspective}

The benefits of mitral repair over replacement for endocarditis are not well established, particularly in terms of recurrence, freedom from reoperation, and survival. This analysis of long-term outcomes of mitral surgery for endocarditis in California and New York State suggests that repair is underused, even though it is associated with better survival and lower recurrence compared with replacement.

See Editorial Commentary page 1913.

See Editorial page 1904.
The benefits of mitral repair over replacement for infective endocarditis are not well established, particularly in terms

\footnotetext{
From the Departments of ${ }^{\mathrm{a} C}$ ardiovascular Surgery, and ${ }^{\mathrm{b}}$ Population Health Science and Policy, Icahn School of Medicine at Mount Sinai; and ${ }^{\mathrm{c}}$ Department of Surgery, Stony Brook University Hospital, New York, NY.

Received for publication Feb 12, 2017; revisions received July 4, 2017; accepted for publication July 30, 2017; available ahead of print Sept 21, 2017.

Address for reprints: Joanna Chikwe, MD, Department of Cardiovascular Surgery, Mount Sinai Medical Center, 1190 Fifth Ave, New York, NY 10029 (E-mail: Joanna.Chikwe@mountsinai.org). $0022-5223 / \$ 36.00$

Copyright @ 2017 Published by Elsevier Inc. on behalf of The American Association for Thoracic Surgery

http://dx.doi.org/10.1016/j.jtcvs.2017.07.077
}

of recurrent infection, long-term freedom from reoperation, and survival. Based primarily on the results reported in single-center case series, current American and European consensus guidelines recommend mitral valve repair over replacement for the surgical treatment of active mitral

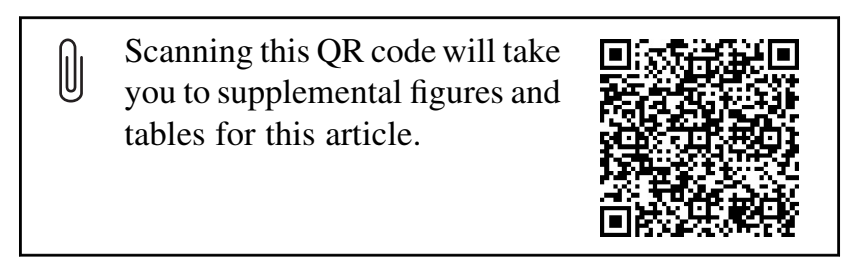




\section{Abbreviations and Acronyms \\ $\mathrm{CI}=$ confidence interval \\ HR $=$ hazard ratio \\ ICD-9-CM = International Classification of \\ Disease, 9th Revision, Clinical \\ Modification}

native valve endocarditis. ${ }^{1-3}$ The long-term outcomes of repair and replacement for native mitral valve endocarditis in contemporary, real-world practice largely are unknown, in part because of the low frequency of infective endocarditis. We therefore conducted a population-based study encompassing patients operated on for active native mitral valve endocarditis in California and New York State.

\section{METHODS}

\section{Study Design and Population}

This retrospective cohort study analyzed long-term outcomes after primary, isolated mitral valve surgery for active native valve endocarditis in patients aged 18 years or older in New York State and California State between 1998 and 2010, according to whether patients underwent mitral valve repair or replacement. Patients were identified with International Classification of Diseases, Ninth Revision, Clinical Modification (ICD-9-CM) procedure codes for mitral valve surgery and replacement $(35.12,35.23,35.24$, or 35.33$)$ and diagnosis codes indicating active infective endocarditis (421.0, 421.1, 421.9, 036.42, 098.84, 112.81, $115.04,115.14$, or 115.94) in mandatory patient discharge databases collated by the New York Statewide Planning and Research Cooperative System and the Office of Statewide Health Planning and Development in California State. These all-payer, administrative databases prospectively collect data on every hospital discharge, ambulatory surgery, and emergency department visit in their respective states. A unique identifier allocated to each patient in each database permits analysis of clinical outcomes after the index admission. The proportion of patients who underwent mitral valve repair versus replacement for infective endocarditis was calculated including 1998 to 2014 data.

Patients were excluded if they underwent concomitant aortic or tricuspid valve surgery; if they had a history of valve surgery, heart transplantation, ventricular assist device placement, or drug abuse; or had surgery more than 6 weeks after admission (Figure E1). Details of exclusion criteria definitions were included in Table E1. Baseline comorbidities were identified from the index hospitalization and all previous hospitalizations (a detailed definition is given in Table E2). Drug abusers were analyzed as a separate subgroup, and the outcomes were compared with the nondrug abuse study cohort. This study was approved by the Data Protection Review Boards of New York State Department of Health; the Committee for the Protection of Human Subjects of California State; and the Program for Protection of Human Subjects at the Icahn School of Medicine at Mount Sinai. The approval included a waiver of informed consent.

\section{Definitions and Code Validation}

ICD-9-CM codes for active infective endocarditis were validated in a subset of patients' medical records. The sensitivity, specificity, and positive predictive value of ICD-9-CM codes to identify active infective endocarditis defined by the modified Duke criteria ${ }^{4}$ were $94 \%, 99 \%$, and $94 \%$, respectively. ${ }^{5}$ Causative micro-organisms were categorized by the use of primary and secondary diagnosis codes as follows: Staphylococcus aureus (including methicillin-resistant species), other Staphylococcus species, Streptococcus species, Gram-negative bacilli, fungus, and unknown (which included culture negative and cases where the organism was not specified).

\section{Study End Points}

The primary endpoint was all-cause mortality, and secondary endpoints were recurrent endocarditis and mitral valve reoperation. Deaths were ascertained from linked state's vital statistics death records, deceased discharge disposition at any subsequent in-hospital and emergency department and ambulatory surgery visits, and additionally from the Social Security Death Master File; recurrent infective endocarditis was defined as a diagnosis of infective endocarditis in the subsequent admissions at least 6 weeks after discharge, based on the period of antibiotics treatment recommended in the current guidelines. ${ }^{6}$ Reoperation was identified as any subsequent mitral valve repair or replacement.

\section{Statistical Analysis}

Normally distributed continuous variables were reported as means with standard deviation and compared with the $t$ test. Categorical variables were expressed as proportions and compared with the $\chi^{2}$ test. Trends in mitral valve surgery were analyzed with the Cochran-Armitage trend test. Survival curves of the primary end point of all-cause mortality were constructed with Kaplan-Meier methodology and compared with log-rank test. Cumulative incidence curves for the secondary end points of recurrence of infective endocarditis and mitral reoperation were constructed with competing risk analysis as death as a competing event and compared with the Gray test. For each endpoint, multivariable Cox regression models were fit controlling for the surgery type (repair vs replacement), baseline comorbidities (age, sex, race, history of hypertension, diabetes, congestive heart failure, chronic kidney disease, coronary artery disease, atrial fibrillation, peripheral vascular disease, chronic obstructive pulmonary disease, liver disease, cancer, cerebrovascular disease, and coagulation disorders), causative organisms, admission year, state of residency, and concomitant coronary artery bypass graft and clustering patients within hospitals. For secondary outcomes with limited number of events, models were selected based on stepwise selection and fit assessed with Akaike Information Criteria. Patient demographics (age, sex, race, state of residency), admission year, and the surgery type were retained and forced into the model. In each model, proportional hazard assumption was evaluated and if violated, the interaction term between time-to-event and the surgery type were incorporated into the model and hazard ratios were calculated at different follow-up time points. For the analysis of recurrence, patients who had mitral valve reoperation before the date of recurrence or last follow-up were not censored at the time of reoperation and remained in the analysis.

As a validation of the results of multivariable analyses, the analyses described previously were repeated for all study end points using inverse probability weighting and propensity score adjustment and cohorts created by propensity score matching (Figure E3). ${ }^{7,8}$ Propensity scores were calculated with a multivariable hierarchical logistic regression model with repair as the outcome and with patients clustered by hospitals. Patients' demographics, baseline comorbidities, causative organisms, and admission year were included in the model as covariates. The area under the receiver operating curve for the model was 0.78 . For propensity matching, 1:2 match was conducted. Each outcome was assessed by fitting Cox regression models with each outcome as a dependent variable and the surgery type as a covariate with a robust sandwich variance estimator. Marginal Cox models with a robust sandwich variance estimator were used to assess the difference in outcomes in matched cohort. The results of this sensitivity analysis confirmed the main findings and are listed in Table E5.

A subgroup analysis of the effect of individual surgeon volume on reoperation within 1 year after repair was conducted with New York State patients (individual surgeon identifiers for California were not available). Surgeons were divided into 2 groups according to whether they performed fewer or more than 25 operations for any etiology on the mitral valve annually. We selected 25 cases as the cut-off based on previous data 


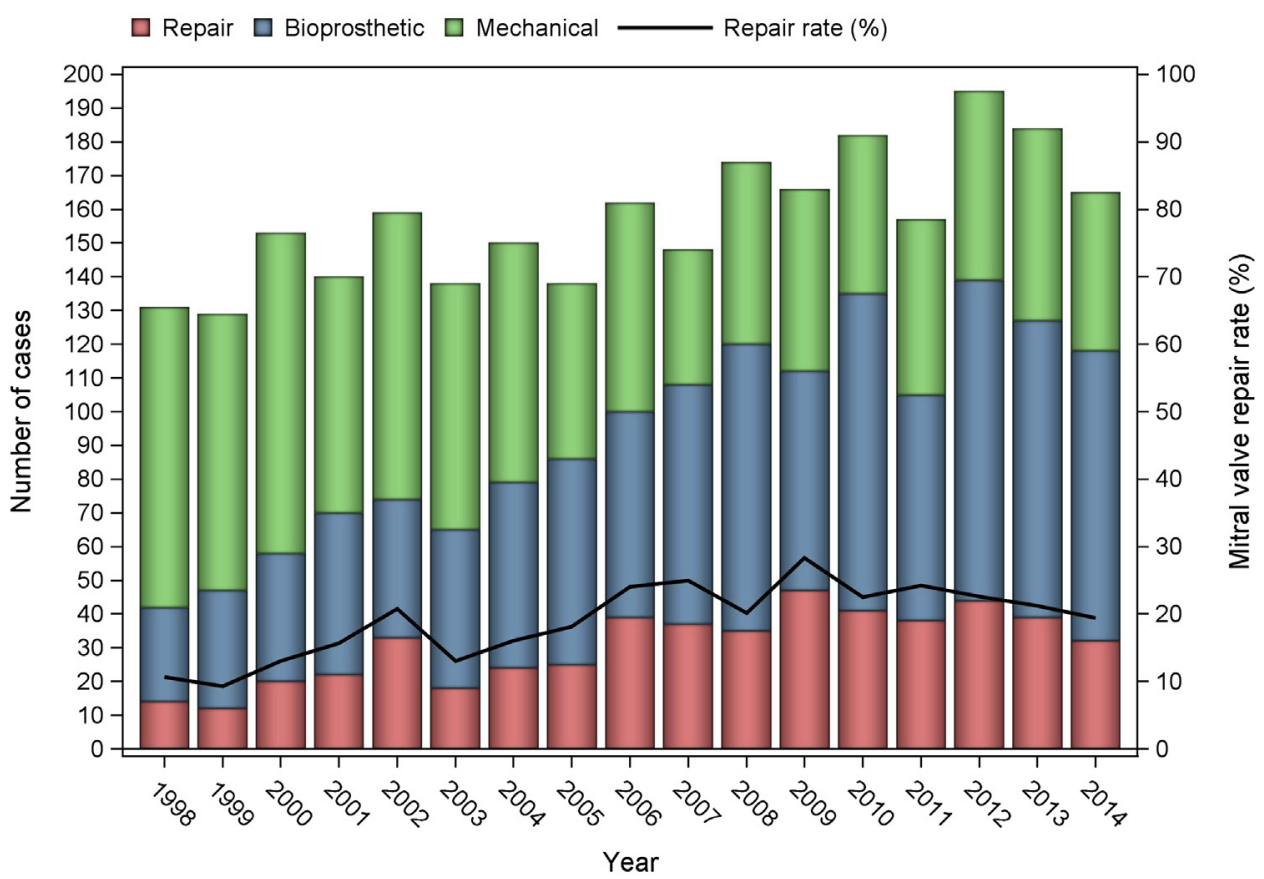

FIGURE 1. Trends in mitral valve surgery for active endocarditis between 1998 and 2014.

suggesting this threshold is associated with improved freedom from early reoperation after mitral repair. ${ }^{9}$ The cumulative incidence of reoperation at 1 year was calculated and compared between these 2 groups by fitting a Cox regression model. Separate subgroup analyses of predictors of survival after repair and comparative outcomes in drug users also were conducted. All tests were 2-tailed, and an alpha level of 0.05 was considered statistically significant. All statistical analyses were performed with SAS version 9.4 (SAS Institute, Cary, NC).

\section{RESULTS}

\section{Study Population}

A total of 88,031 adult patients (42,647 [48.5\%] in New York State and 45,384 [51.6\%] in California State) who had primary mitral valve surgery for any etiologies between 1998 and 2010 were identified. Among these, 3976 patients $(4.5 \%)$ were admitted to hospital with infective endocarditis. Patients who underwent concomitant aortic or tricuspid surgery $(38.9 \%, \mathrm{n}=1548)$ or who had a history of valve surgery $(7.4 \%, \mathrm{n}=296)$, heart transplant or ventricular assist device placement $(<0.4 \%, \mathrm{n}<15)$, or drug abuse $(15.2 \%$, $\mathrm{n}=603$ ) were excluded, leaving 1970 patients as a study cohort. Among these patients, 367 patients $(18.6 \%)$ underwent mitral valve repair and $1603(81.4 \%)$ underwent mitral replacement. The median follow-up time was 7.1 years (range $0-12$ years) in the repair group and 6.5 years (range $0-12$ years) in the replacement group. The propensity-matched cohort included 798 patients: 266 in the repair group and 532 in the replacement group (median follow-up time was 7.2 years [range 0-12 years] and 6.5 years [range 0-12 years], respectively). There were no significant differences in baseline demographics or comorbidities between repair and replacement groups in the matched cohort (Table E3).

\section{Trends in Mitral Valve Surgery for Native Valve Endocarditis}

The rate of mitral valve repair increased from $10.7 \%$ in 1998 to $19.4 \%$ in $2014(P<.001)$ (Figure 1$)$. Patients underwent surgery in 164 hospitals (45 hospitals in New York State and 119 hospitals in California State). Between 1998 and 2014, the total institutional volume of isolated active mitral native valve endocarditis ranged from 1 to 107 cases, with a median of 10 cases. The median mitral repair rate was $12 \%$, ranging from 0 to $100 \%$ (Figure E2, A). The number of surgeons who operated on at least 1 patient with isolated active mitral native valve endocarditis in New York State was 264. The total number of operations for each surgeon ranged from 1 to 39 cases, with a median of 2 cases. Among surgeons who operated on more than 5 endocarditis cases, the median repair rate was $14.3 \%$, ranging from $0 \%$ to $84 \%$ (Figure E2, $B$ ). Among patients who underwent replacement, the proportion of bioprosthetic valve use significantly increased from $23.9 \%$ in 1998 to $64.7 \%$ in $2014(P<.001)$.

\section{Patient Characteristics}

Patients who underwent mitral repair were younger (mean age $54.9 \pm 15.3$ vs $57.4 \pm 14.6$ years, $P=.005$ ) and had fewer comorbidities; for example, in the repair group, $46.3 \%$ had congestive heart failure compared with $57.1 \%$ in the replacement group $(P<.001)$ (Table 1$)$. Patients undergoing mitral repair also were less likely to have a virulent organism; $21.3 \%$ in the repair group had Staphylococcal endocarditis compared with more than $30 \%$ in the replacement group $(P<.001)$ (Table 1$)$. 
TABLE 1. Demographics of patients according to whether a patient had a mitral repair versus replacement

\begin{tabular}{|c|c|c|c|c|c|}
\hline Variable & $\begin{array}{c}\text { Total } \\
(\mathbf{n}=\mathbf{1 9 7 0})\end{array}$ & $\begin{array}{l}\text { Mitral valve repair } \\
\qquad(\mathrm{n}=367)\end{array}$ & $\begin{array}{l}\text { Mitral valve replacement } \\
\qquad(\mathbf{n}=\mathbf{1 6 0 3})\end{array}$ & $\begin{array}{l}\text { Standardized } \\
\text { difference, } \%\end{array}$ & $P$ value \\
\hline \multicolumn{6}{|l|}{ Demographics } \\
\hline Age, y & $56.9 \pm 14.8$ & $54.9 \pm 15.3$ & $57.4 \pm 14.6$ & 16.2 & .005 \\
\hline Male & $1143(58.0)$ & $243(66.2)$ & $900(56.1)$ & 20.8 & $<.001$ \\
\hline \multicolumn{6}{|l|}{ Race } \\
\hline White & $1379(70.0)$ & $273(74.4)$ & $1106(69.0)$ & 12.0 & .04 \\
\hline Black & $197(10.0)$ & $29(7.9)$ & $168(10.5)$ & 8.9 & .14 \\
\hline Others & $394(20.0)$ & $65(17.7)$ & $329(20.5)$ & 7.2 & .22 \\
\hline Residency in California & $1057(53.7)$ & $186(50.7)$ & $871(54.3)$ & 7.3 & .21 \\
\hline \multicolumn{6}{|l|}{ Comorbidities } \\
\hline Hypertension & $1056(53.6)$ & 175 (47.7) & $881(55.0)$ & 14.6 & .01 \\
\hline Diabetes & 234 (11.9) & $31(8.4)$ & 203 (12.7) & 13.8 & .02 \\
\hline Coronary artery disease & $841(42.7)$ & $146(39.8)$ & $695(43.4)$ & 7.3 & .21 \\
\hline Atrial fibrillation & $490(24.9)$ & $85(23.2)$ & $405(25.3)$ & 4.9 & .40 \\
\hline Peripheral vascular disease & $245(12.4)$ & $37(10.1)$ & $208(13.0)$ & 9.1 & .13 \\
\hline Congestive heart failure & $1085(55.1)$ & $170(46.3)$ & $915(57.1)$ & 21.7 & $<.001$ \\
\hline Cerebrovascular disease & $508(25.8)$ & $85(23.2)$ & $423(26.4)$ & 7.5 & .20 \\
\hline Chronic obstructive pulmonary disease & $337(17.1)$ & $62(16.9)$ & $275(17.2)$ & 0.7 & .90 \\
\hline Chronic kidney failure & $480(24.4)$ & $77(21.0)$ & $403(25.1)$ & 9.9 & .09 \\
\hline Dialysis dependent & $349(17.7)$ & $50(13.6)$ & $299(18.7)$ & 13.7 & .02 \\
\hline Liver disease & $232(11.8)$ & $41(11.2)$ & $191(11.9)$ & 2.3 & .69 \\
\hline Cancer & $226(11.5)$ & $38(10.4)$ & $188(11.7)$ & 4.4 & .46 \\
\hline Coagulation disorders & $332(16.9)$ & $54(14.7)$ & $278(17.3)$ & 7.2 & .23 \\
\hline \multicolumn{6}{|l|}{ Pathogen } \\
\hline Staphylococcus & $591(30.0)$ & $78(21.3)$ & $513(32.0)$ & 24.5 & $<.001$ \\
\hline$S$ aureus & $487(24.7)$ & $67(18.3)$ & $420(26.2)$ & 19.2 & .002 \\
\hline MRSA & $145(7.4)$ & $25(6.8)$ & $120(7.5)$ & 2.6 & .66 \\
\hline Streptococcus & $600(30.5)$ & $110(30.0)$ & 490 (30.6) & 1.3 & .82 \\
\hline Oral streptococcus & 327 (16.6) & $62(16.9)$ & $265(16.5)$ & 1.0 & .87 \\
\hline Gram negative & $101(5.1)$ & $15(4.1)$ & $86(5.4)$ & 6.0 & .32 \\
\hline Fungus & 27 (1.4) & $<15(<4.1)^{*}$ & $23(1.4)$ & 3.1 & .61 \\
\hline Concomitant coronary artery bypass graft & 367 (18.6) & $62(16.9)$ & $305(19.0)$ & 5.6 & .34 \\
\hline
\end{tabular}

Values are $\mathrm{n}(\%)$, or mean \pm standard deviation, unless otherwise indicated. MRSA, Methicillin-resistant Staphylococcus aureus. *Small cell sizes (numbers $<15)$ are suppressed based on Data Use Agreement with the Statewide Planning and Research Cooperative System and Office of Statewide Health Planning and Development in California.

\section{Mortality}

The 30-day mortality after mitral valve repair for endocarditis was $3.5 \%$ versus $8.4 \%$ for mitral valve replacement $(P=.001)$ and 90 -day mortality was $6.0 \%$ for repair versus $14.7 \%$ for replacement $(P<.001)$. Mitral repair was associated with significantly better survival at 12 years than mitral replacement (adjusted hazard ratio $[\mathrm{HR}], 0.71 ; 95 \% \mathrm{CI}, 0.57-0.88 ; P=.002)$ and was $68.8 \%(95 \%$ confidence interval $[\mathrm{CI}], 62.5 \%-74.3 \%)$ versus $53.5 \% \quad(95 \%$ CI, 50.6\%-56.4\%) respectively (Figure 2). Significant predictors of late mortality included end-stage renal disease (adjusted HR, 2.62; 95\% CI, 2.04-3.37; $P<.001)$ and causative organism. Patients with Staphylococcus endocarditis had worse survival than patients with Streptococcus endocarditis (adjusted HR, 1.54; 95\% CI, 1.26-1.89; $P<.001$ ) (Table E4). The results of the sensitivity analysis are included in Table E5.

\section{Recurrence of Infective Endocarditis}

Mitral repair was associated with a significantly lower rate of recurrent endocarditis than replacement. The cumulative incidence of recurrent infective endocarditis at 12 years was $4.7 \%(95 \% \mathrm{CI}, 2.8 \%-7.2 \%)$ in the repair group and $9.5 \%(95 \% \mathrm{CI}, 8.0 \%-11.1 \%)$ in the replacement group (Gray test, $P=.02$ ). The repair group and the replacement group had a similar risk of recurrence of endocarditis up to one year after surgery (adjusted HR at 1 year $0.70 ; 95 \%$ CI, 0.43-1.16; $P=.17$ ). After 1 year, repair was associated with significantly lower risk of recurrence than replacement (adjusted HR at 2 years 0.47 ; $95 \%$ CI, 0.26-0.83;P=.009) and the relative risk continued to decrease over 5 years (adjusted HR at 5 years $0.14 ; 95 \%$ CI, 0.03-0.62; $P=.01$ ) (Figure 3). (The final Cox regression model is included in Table E4, and the result of the sensitivity analysis is included in Table E5. The 30-day mortality of recurrent endocarditis was $15.0 \%$. 


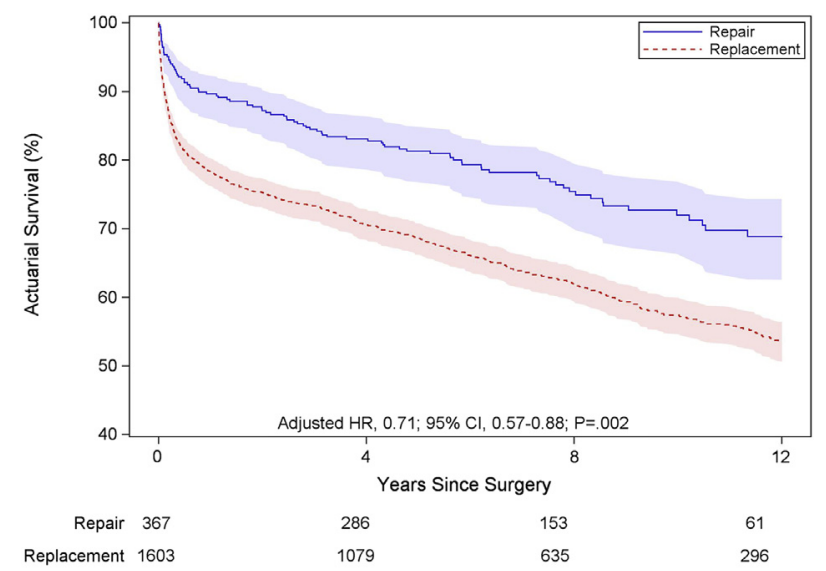

FIGURE 2. Long-term survival for patients who had mitral valve surgery for native valve endocarditis. The shaded areas represent $95 \%$ confidence intervals for each outcome. $H R$, Hazard ratio; $C I$, confidence interval.

\section{Mitral Reoperation and Surgeon Volume}

The cumulative incidence of mitral reoperation at 12 years was $9.1 \%(95 \% \mathrm{CI}, 6.2 \%-12.8 \%)$ after mitral repair and $8.6 \%(95 \% \mathrm{CI}, 7.1 \%-10.4 \%)$ after mitral replacement (Gray test, $P=.12$ ). Patients who underwent repair had a greater risk of reoperation than those who underwent replacement up to 1 year after surgery (adjusted HR at 1 year $1.98 ; 95 \%$ CI, 1.28-3.05; $P=.002$ ). After 1 year, the relative risk of mitral reoperation between repair and replacement was not significant (adjusted HR at 2 years 1.41 ; $95 \%$ CI, 0.90-2.21 and adjusted HR at 5 years 0.51 ; 95\% CI, 0.21-1.24) (Figure 4). The final Cox regression model is included in Table E4, and the result of the sensitivity analysis is included in Table E5. The 30-day mortality after reoperation on the mitral valve was $6.5 \%$.

Within New York State, we identified 249 patients who underwent mitral repair for active endocarditis between

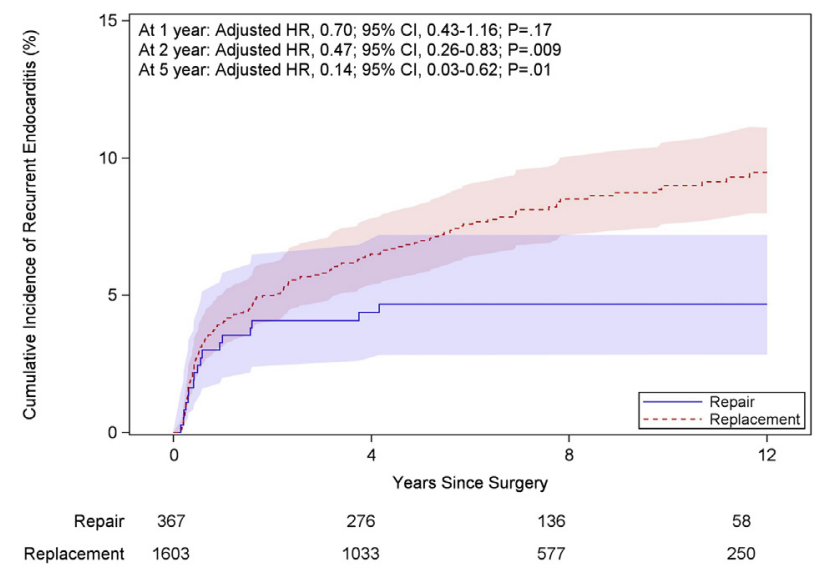

FIGURE 3. Cumulative incidence of recurrent endocarditis for patients who had mitral surgery for active mitral endocarditis. The shaded areas represent $95 \%$ confidence intervals for each outcome. $H R$, Hazard ratio; CI, confidence interval.

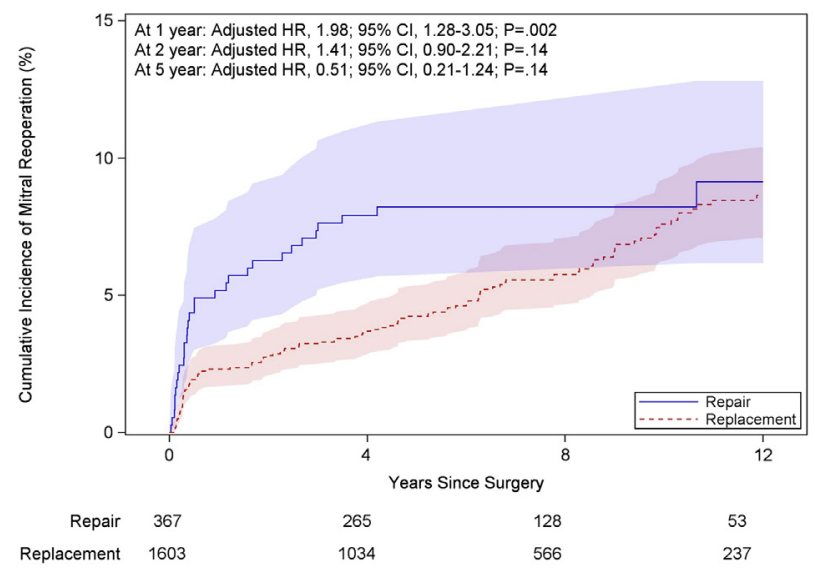

FIGURE 4. Cumulative incidence of mitral reoperation for patients who had mitral surgery for active mitral endocarditis. The shaded areas represent $95 \%$ confidence intervals for each outcome. $H R$, Hazard ratio; $C I$, confidence interval.

1998 and 2014: 98 patients (39.4\%) were operated by surgeons whose annual total case volume for mitral valve disease of any etiology was less than 25 operations, and the remaining 151 patients $(60.6 \%)$ were operated on by surgeons whose annual total mitral volume was 25 or more operations. The cumulative incidence of reoperation at 1 year was significantly greater at $9.2 \%(95 \% \mathrm{CI}$, $4.5 \%-16.0 \%$ ) for patients operated by surgeons with an annual mitral volume of fewer than 25 cases, than it was for patients operated by surgeons with annual mitral volume of 25 or more for whom the cumulative incidence of reoperation within 1 year was $2.0 \% \quad(95 \% \quad \mathrm{CI}$, $0.6 \%-5.4 \%$ ) (adjusted HR $0.18 ; 95 \% \mathrm{CI}, 0.05-0.75$, $P=.02)$.

\section{Drug Abusers}

The number of drug abusers who underwent primary isolated mitral valve surgery for active endocarditis with the same exclusion criteria as the study cohort was 313 . Drug abusers were much younger (mean age $43.6 \pm 11.2$ vs $56.9 \pm 14.8$ years, $P<.01$ ) than nondrug abusers, but they had significantly worse survival at 12 years $(51.3 \%$ $[95 \%$ CI, $44.7 \%-57.4 \%] \quad$ vs $56.2 \% \quad[95 \%$ CI, $53.6 \%-58.8 \%$ ], adjusted HR, 1.65 ; 95\% CI, 1.39-1.96; $P<.001)$. The commonest organism was Staphylococcus (42.2\% of cases, compared with $30.0 \%$ in nondrug users). In the cohort of drug abusers, the overall repair rate was $18.2 \%(\mathrm{n}=57)$. Twelve-year survival was $55.0 \%(95 \%$ CI, $36.7 \%-70.2 \%$ ) in the repair group versus $50.7 \%$ $(95 \% \mathrm{CI}, 43.7 \%-57.3 \%)$ in the replacement group (adjusted HR, 0.58; 95\% CI, 0.36-0.94; $P=.03$ ). The cumulative incidence of recurrent endocarditis at 12 years was $10.7 \%(95 \% \mathrm{CI}, 4.3 \%-20.5 \%)$ in the repair group versus $22.6 \%$ (95\% CI, $17.3 \%-28.3 \%)$ in the replacement group (adjusted HR, 0.44; 95\% CI, 0.20-0.94; $P=.04$ ). The 
cumulative incidence of mitral reoperation at 12 years was $5.3 \%(95 \%$ CI, $1.4 \%-13.4 \%)$ in the repair group versus $22.8 \%$ (95\% CI, $16.9 \%-29.2 \%)$ in the replacement group (adjusted HR, 0.31; 95\% CI, 0.07-1.35; $P=.12$ ).

\section{DISCUSSION}

In this analysis of patients in California and New York State undergoing isolated mitral valve surgery for active infective endocarditis, mitral valve repair was associated with increased 12-year survival and lower risk of recurrent endocarditis. Mitral repair and replacement had similar 12-year reoperation risk, but the reoperation risk after mitral valve repair was 5 times greater when repair was performed by low-volume surgeons. Repair is increasingly favored in this contemporary, real-world practice setting but overall repair rates remain low at $20 \%$, with a very wide spread in individual surgeon repair rates.

Active native mitral valve endocarditis encompasses a wide spectrum of disease-from isolated single segment perforations or vegetations requiring very simple repair techniques, to extensive destruction of the valve leaflet tissue and annular support requiring complex valve reconstruction or replacement. In addition, valve repair is often made more challenging by the common finding that infective endocarditis is superimposed on pre-existing valve pathology such as leaflet prolapse. This study was not designed to differentiate between the spectrum of severity of endocarditis, and it is possible that the mortality benefit that we observed with repair over replacement reflects the greater burden of valve disease in patients who underwent replacement.

The risk of recurrent endocarditis was similar for the first year after repair compared with replacement, but by 2 years patients who had undergone replacement were twice as likely as those that had undergone repair to be diagnosed with recurrent endocarditis, and by 5 years they were 10 times more likely to experience recurrent endocarditis. From what is currently understood about the pathophysiology of early and late recurrence of endocarditis, it seems likely that incomplete treatment and nosocomial (including intraoperative contamination) was equally likely to occur in patients undergoing repair or replacement; however, late reinfection was significantly more likely to occur in patients with prosthetic valves than in patients with repaired valves. This finding may have implications for consensus guideline recommendations for antibiotic prophylaxis after valve surgery, which currently do not discriminate between patients who have undergone valve repair versus replacement. ${ }^{10}$ Perhaps more importantly, the superior freedom from recurrent endocarditis may be the primary rationale for favoring repair over replacement where feasible.

The current state of surgery for native mitral valve endocarditis captured in this registry is one of wide variations in repair rates, and failure of repair within 1 year. The overall repair rate was low, at around $20 \%$, and it may be possible that this was dictated by severity of valve disease encountered. However, the existence of single-center reports of repair rates of $42 \%$ to $80 \%$ which include valves with extensive destruction, ${ }^{11-18}$ taken together with the wide variation in repair rates between individual surgeons and institutions observed in our analysis, suggest that surgeon experience may have an important role to play. This hypothesis is supported by our finding that mitral valve repairs performed by higher volume surgeons for endocarditis were five times less likely to require reoperation within 1 year than mitral valve repairs performed by lower volume surgeons. This finding is not unique to infective endocarditis and, in our opinion, underlines the value of concentrating surgeon experience, particularly given the fact that these patients are rarely true surgical emergencies. 9,19-23

\section{Strength and Limitations}

The main strength of our study lies in the unselected surgical population with comprehensive long-term outcome data capturing recurrent endocarditis and reoperations - complications that tend to be underestimated in single-center studies in which follow-up may be limited to patients attending the same institution. The main and important limitation of our study is our inability to adjust for the severity of endocarditis, as detailed previously, and consequently it is possible that the superior outcomes observed after repair may be explained by these confounding variables. In addition, it is well recognized that the use of an administrative rather than a clinical dataset may lead to less accurate identification of endocarditis and other patient factors: however, we validated our data against clinical records and obtained high positive predictive values for the identification of active endocarditis. The ICD-9-CM codes do not allow us to distinguish reliably between drug users who are injecting and noninjecting. Finally, the secondary outcomes of patients who moved to different states or country were not captured and may therefore have been underestimated, although we believe this would affect patients undergoing repair and replacement equally.

\section{CONCLUSIONS}

Mitral valve repair for active mitral valve endocarditis is associated with improved long-term survival and lower rates of recurrent endocarditis than mitral valve replacement. The overall repair rates of active mitral endocarditis remain very low, with wide variation in repair rates and durability observed among individual surgeons and institutions. This analysis provides data supporting consensus guidelines that mitral valve repair is preferred over replacement for the surgical treatment of active native 
valve endocarditis and also suggests that concentrating surgeon experience may address some of the disparities currently observed in patient outcomes.

\section{Conflicts of Interest Statement}

Dr Chikwe received speaker honoraria from Edwards Lifesciences. The Icahn School of Medicine at Mount Sinai receives royalty payments from Edwards Lifesciences and Medtronic for intellectual property related to Dr Adams' involvement in the development of 2 mitral valve repair rings and one tricuspid valve repair ring. Dr Adams is the National Co-Principal Investigator of the CoreValve United States Pivotal Trial, which is supported by Medtronic. All other authors have nothing to disclose with regard to commercial support. None of the sponsoring organizations had any role in the design and conduct of the study; collection, management, analysis, and interpretation of the data; preparation, review, or approval of the manuscript; or decision to submit the manuscript for publication.

\section{References}

1. AATS Surgical Treatment of Infective Endocarditis Consensus Guidelines Writing Committee Chairs, Writing Committee, Pettersson GB, Coselli JS, Hussain ST, Griffin B, Blackstone EH, Gordon SM, et al. 2016 The American Association for Thoracic Surgery (AATS) consensus guidelines: surgical treatment of infective endocarditis: Executive summary. J Thorac Cardiovasc Surg. 2017;153:1241-58.

2. Nishimura RA, Otto CM, Bonow RO, Carabello BA, Erwin JP III, Fleisher LA, et al. 2017 AHA/ACC Focused Update of the 2014 AHA/ACC Guideline for the Management of Patients With Valvular Heart Disease: A Report of the American College of Cardiology/American Heart Association Task Force on Clinical Practice Guidelines. Circulation. 2017;70:252-89.

3. Habib G, Lancellotti P, Antunes MJ, Bongiorni MG, Casalta JP, Del Zotti F, et al 2015 ESC Guidelines for the management of infective endocarditis: The Task Force for the Management of Infective Endocarditis of the European Society of Cardiology (ESC). Endorsed by: European Association for Cardio-Thoracic Surgery (EACTS), the European Association of Nuclear Medicine (EANM). Eur Heart J. 2015;36:3075-128.

4. Li JS, Sexton DJ, Mick N, Nettles R, Fowler VG Jr, Ryan T, et al. Proposed modifications to the Duke criteria for the diagnosis of infective endocarditis. Clin Infect Dis. 2000;30:633-8.

5. Toyoda N, Chikwe J, Itagaki S, Gelijns AC, Adams DH, Egorova N. Trends in infective endocarditis in California and New York State, 1998-2013. JAMA. 2017:317:1652-60

6. Baddour LM, Wilson WR, Bayer AS, Fowler VG Jr, Tleyjeh IM, Rybak MJ, et al. Infective endocarditis in adults: diagnosis, antimicrobial therapy, and management of complications: a scientific statement for healthcare professionals from the American Heart Association. Circulation. 2015;132:1435-86.

7. Brookhart MA, Wyss R, Layton JB, Sturmer T. Propensity score methods for confounding control in nonexperimental research. Circ Cardiovasc Qual Outcomes. 2013;6:604-11.
8. Elze MC, Gregson J, Baber U, Williamson E, Sartori S, Mehran R, et al. Comparison of propensity score methods and covariate adjustment: evaluation in 4 cardiovascular studies. J Am Coll Cardiol. 2017;69:345-57.

9. Chikwe J, Toyoda N, Anyanwu A, Itagaki S, Egorova NN, Boateng P, et al. Surgeon mitral volume impact on valve repair rates, durability and survival in New York State. J Am Coll Cardiol. April 24, 2017 [Epub ahead of print].

10. Wilson W, Taubert KA, Gewitz M, Lockhart PB, Baddour LM, Levison M, et al Prevention of infective endocarditis: guidelines from the American Heart Association: a guideline from the American Heart Association Rheumatic Fever, Endocarditis, and Kawasaki Disease Committee, Council on Cardiovascular Disease in the Young, and the Council on Clinical Cardiology, Council on Cardiovascular Surgery and Anesthesia, and the Quality of Care and Outcomes Research Interdisciplinary Working Group. Circulation. 2007;116: 1736-54.

11. de Kerchove L, Price J, Tamer S, Glineur D, Momeni M, Noirhomme P, et al. Extending the scope of mitral valve repair in active endocarditis. $J$ Thorac Cardiovasc Surg. 2012;143:S91-5.

12. de Kerchove L, Vanoverschelde JL, Poncelet A, Glineur D, Rubay J, Zech F, et al. Reconstructive surgery in active mitral valve endocarditis: feasibility, safety and durability. Eur J Cardiothorac Surg. 2007;31:592-9.

13. Dreyfus G, Serraf A, Jebara VA, Deloche A, Chauvaud S, Couetil JP, et al. Valve repair in acute endocarditis. Ann Thorac Surg. 1990;49:706-11; discussion 712-3.

14. Iung B, Rousseau-Paziaud J, Cormier B, Garbarz E, Fondard O, Brochet E, et al. Contemporary results of mitral valve repair for infective endocarditis. J Am Coll Cardiol. 2004;43:386-92.

15. Muehrcke DD, Cosgrove DM III, Lytle BW, Taylor PC, Burgar AM, Durnwald CP, et al. Is there an advantage to repairing infected mitral valves? Ann Thorac Surg. 1997;63:1718-24.

16. Ruttmann E, Legit C, Poelzl G, Mueller S, Chevtchik O, Cottogni M, et al. Mitral valve repair provides improved outcome over replacement in active infective endocarditis. J Thorac Cardiovasc Surg. 2005;130:765-71.

17. Shang E, Forrest GN, Chizmar T, Chim J, Brown JM, Zhan M, et al. Mitral valve infective endocarditis: benefit of early operation and aggressive use of repair. Ann Thorac Surg. 2009;87:1728-33; discussion 1734.

18. Wang TK, Oh T, Voss J, Gamble G, Kang N, Pemberton J. Valvular repair or replacement for mitral endocarditis: 7-year cohort study. Asian Cardiovasc Thorac Ann. 2014;22:919-26.

19. Bolling SF, Li S, O'Brien SM, Brennan JM, Prager RL, Gammie JS. Predictors of mitral valve repair: clinical and surgeon factors. Ann Thorac Surg. 2010;90: 1904-11; discussion 1912.

20. Gammie JS, O'Brien SM, Griffith BP, Ferguson TB, Peterson ED. Influence of hospital procedural volume on care process and mortality for patients undergoing elective surgery for mitral regurgitation. Circulation. 2007;115: $881-7$.

21. LaPar DJ, Ailawadi G, Isbell JM, Crosby IK, Kern JA, Rich JB, et al. Mitral valve repair rates correlate with surgeon and institutional experience. J Thorac Cardiovasc Surg. 2014;148:995-1003; discussion 1003-4.

22. Bridgewater B, Hooper T, Munsch C, Hunter S, von Oppell U, Livesey S, et al. Mitral repair best practice: proposed standards. Heart. 2006;92: 939-44.

23. McCarthy PM. When is your surgeon good enough? When do you need a "referent surgeon?" Curr Cardiol Rep. 2009;11:107-13.

Key Words: mitral valve repair, mitral valve replacement, endocarditis, mitral valve endocarditis 


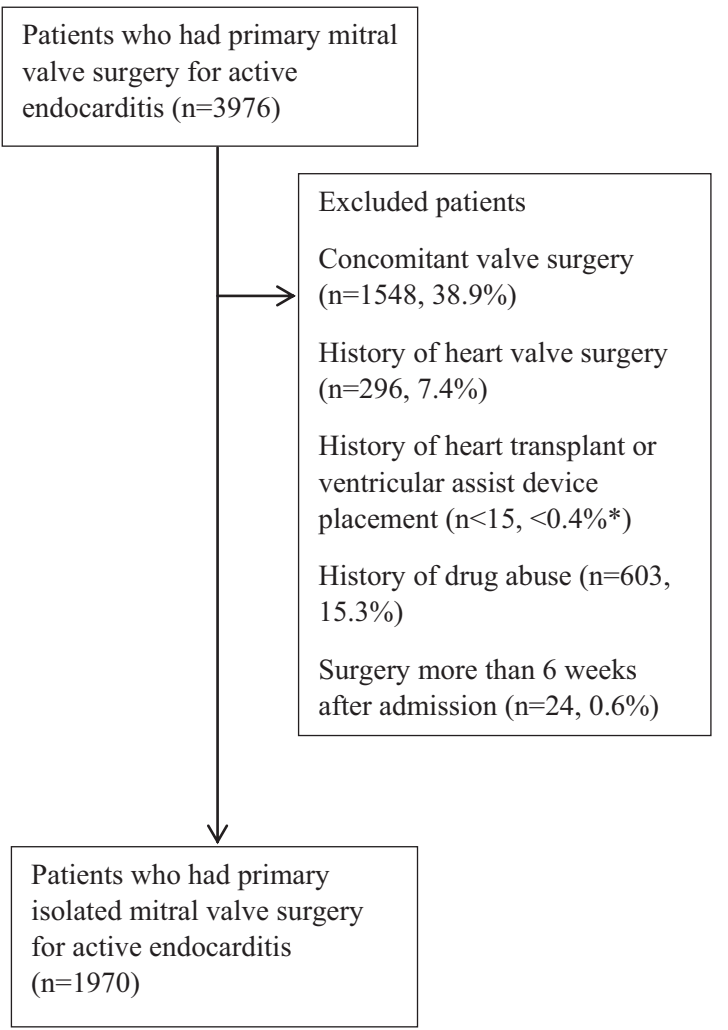

FIGURE E1. Diagram of selection of patients in the study. *Small cell sizes (numbers <15) are suppressed based on Data Use Agreement with the Statewide Planning and Research Cooperative System and Office of Statewide Health Planning and Development in California. 

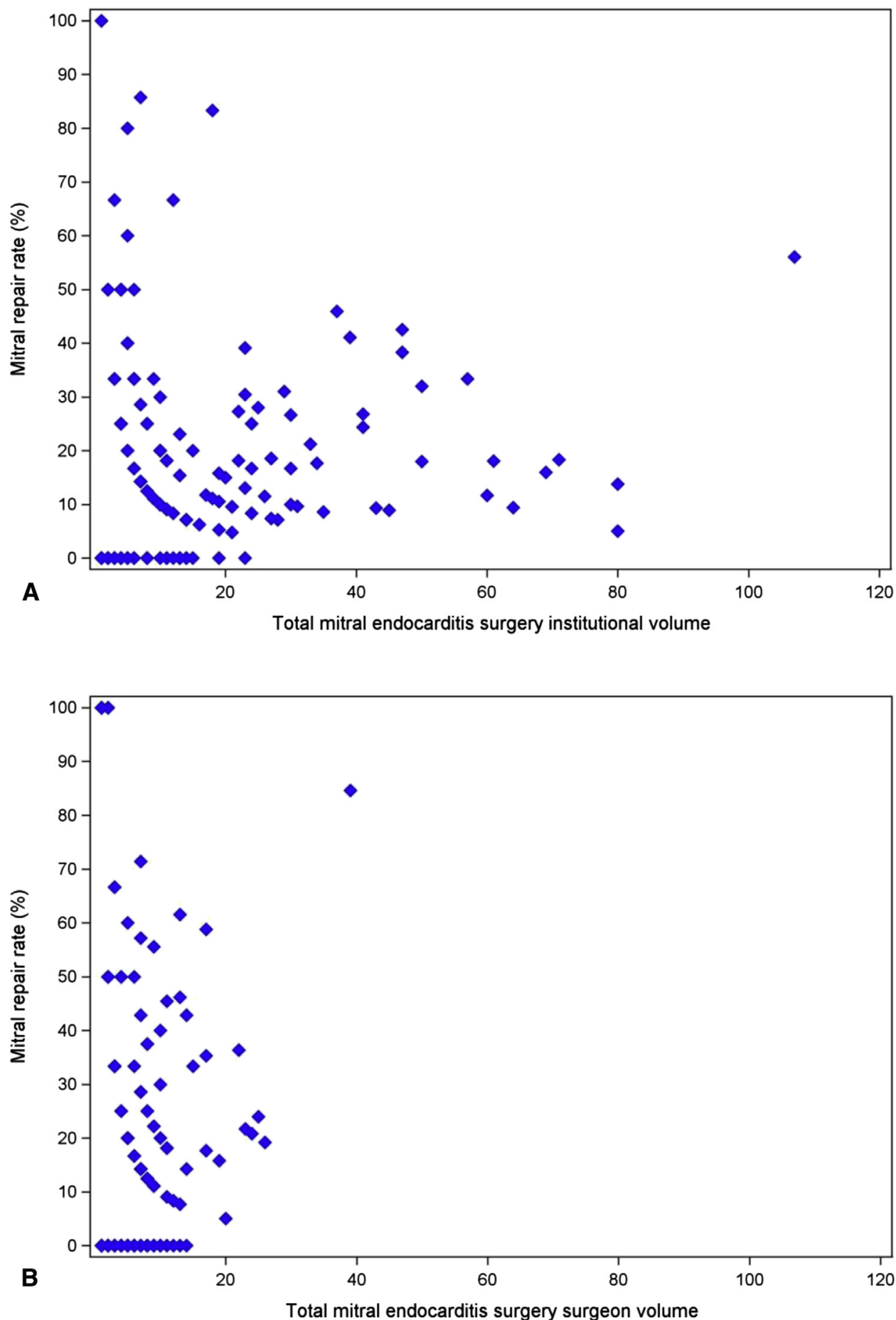

FIGURE E2. Association between total a number of mitral surgery performed on infective endocarditis patients 1998-2012 and a mitral repair rate by (A) institution and (B) surgeon. 


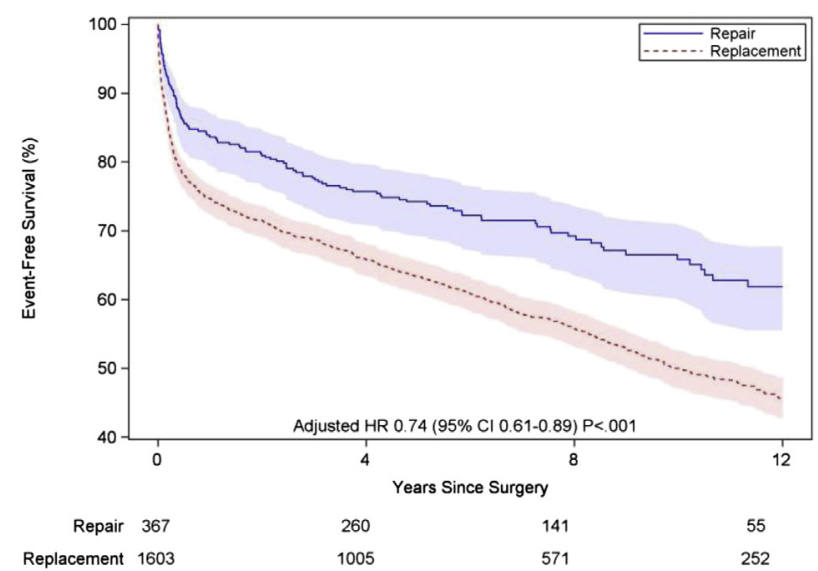

FIGURE E3. Event-free survival after mitral repair versus replacement for infective endocarditis. Patients who had mitral repair had significantly better event-free survival at 12 years $(61.9 \%$ [ $95 \%$ CI, 55.5\%-67.7\%] vs 45.7 [95\% CI, 42.8-48.6]) (adjusted HR, 0.74; 95\% CI, 0.61-0.89; $P<.001)$. $H R$, hazard ratio; $C I$, Confidence interval.

TABLE E1. ICD-9-CM codes for exclusion

\begin{tabular}{|c|c|}
\hline Definition & ICD-9-CM code \\
\hline Concomitant valve surgery & $\begin{array}{l}\text { Procedure codes (from previous admissions) } \\
\quad 3510,3511,3513,3514,3521,3522,3525,3526,3527 \text {, and } 3528\end{array}$ \\
\hline History of valve surgery & $\begin{array}{l}\text { Diagnosis codes (from index and previous admissions) } \\
\quad 99602,99671, \text { V } 433 \text {, and V422 } \\
\text { Procedure codes (previous admissions) } \\
\quad 3510,3511,3513,3514,3521,3522,3525,3526,3527 \text {, and } 3528\end{array}$ \\
\hline $\begin{array}{l}\text { History of transplant or ventricular } \\
\text { assist device placement }\end{array}$ & $\begin{array}{l}\text { Diagnosis codes (from index and previous admissions) } \\
\text { V421, V4321, V4322, and V432 } \\
\text { Procedure codes (from previous admissions) } \\
3752,3753,3754,3763,3766 \text {, and } 3755\end{array}$ \\
\hline Drug abusers & 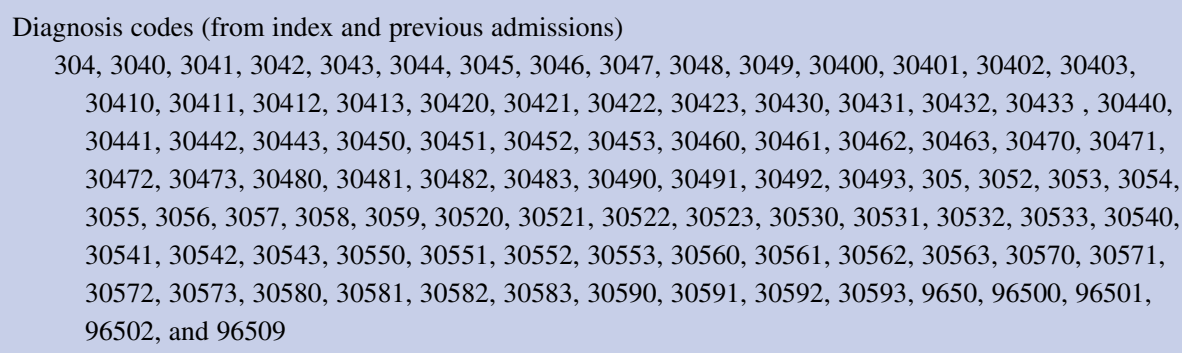 \\
\hline
\end{tabular}

ICD-9-CM, The International Classification of Diseases, Ninth Revision, Clinical Modification. 
TABLE E2. ICD-9-CM codes for baseline comorbidities and causative organisms

\begin{tabular}{|c|c|}
\hline Definition & ICD-9-CM code \\
\hline \multicolumn{2}{|l|}{ Comorbidities } \\
\hline Hypertension & 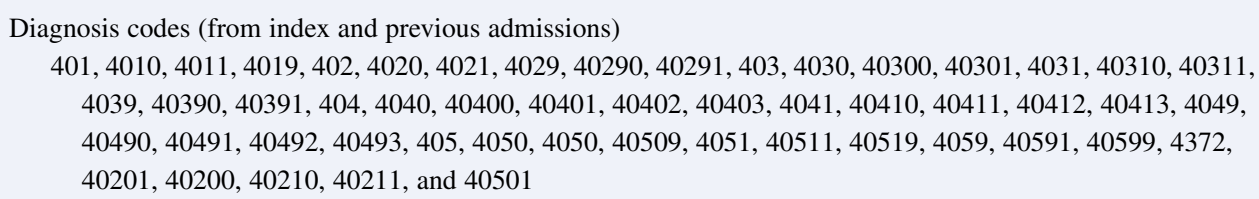 \\
\hline Diabetes & $\begin{array}{l}\text { Diagnosis codes (from index and previous admissions) } \\
\quad 2504,25040,25041,25042,25043,2505,25050,25051,25052,25053,2506,25060,25061,25062,25063 \text {, } \\
\quad 2507,25070,25071,25072,25073,2509,25090,25091,25092,25093\end{array}$ \\
\hline Congestive heart failure & $\begin{array}{l}\text { Diagnosis codes (from index and previous admissions) } \\
\text { 39891, 428, 4280, 4281, 4282, 42820, 42821, 42822, 42823, 4283, 42830, 42831, 42832, 42833, 4284, 42840, } \\
\text { 42841, 42842, 42843, 4289, 429, 4290, 4291, 4292, 4293, 4294, 4295, 4296, 4297, 42971, 42979, 4298, } \\
\text { 42981, 42982, 42983, 42989, and 4299 }\end{array}$ \\
\hline Chronic kidney disease & $\begin{array}{l}\text { Diagnosis codes (index and previous admissions) } \\
\quad 403,4030,40300,40301,4031,40310,40311,4039,40390,40391,404,4040,40400,40401,40402,40403, \\
\quad 4041,40410,40411,40412,40413,4049,40490,40491,40492,40493,585,5851,5852,5853,5854,5855, \\
5859,586, \text { V420, V56, V560, V561, V562, V563, V5631, V5632, V568, 5856, V451, V4511, and V4512 } \\
\text { Dialysis dependent } \\
\text { 40301, 40311, 40402, 40403, 40412, 40413, 40492, V420, V56, V560, V561, V562, V563, V5631, V5632, } \\
\quad \text { V568, 5856, V451, V4511, and V4512 }\end{array}$ \\
\hline Coronary artery disease & 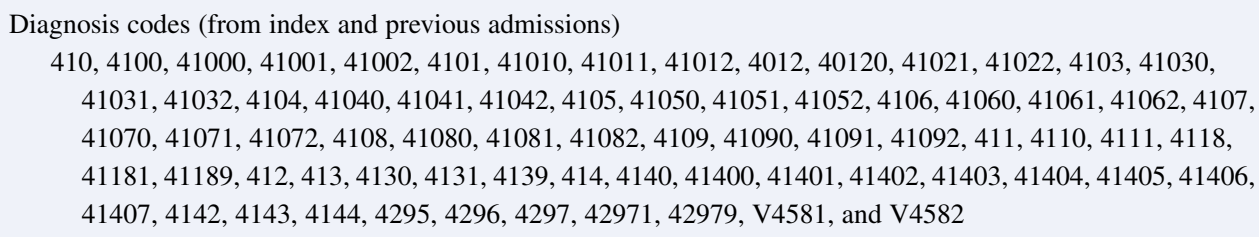 \\
\hline Atrial fibrillation & $\begin{array}{l}\text { Diagnosis codes (from index and previous admissions) } \\
\quad 4273,42731 \text {, and } 42732\end{array}$ \\
\hline Peripheral vascular disease & $\begin{array}{l}\text { Diagnosis codes (from index and previous admissions) } \\
\quad 4400,4401,4402,44020,44021,44022,44023,44024,44029,4403,44030,44031,44032,4404,4408,4409 \text {, } \\
\quad 4471,9961,99662,99674 \text {, and V434 }\end{array}$ \\
\hline $\begin{array}{l}\text { Chronic obstructive } \\
\text { pulmonary disease }\end{array}$ & 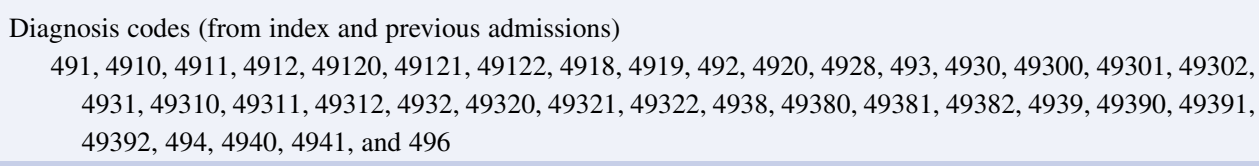 \\
\hline Liver disease & $\begin{array}{l}\text { Diagnosis codes (from index and previous admissions) } \\
\text { 070, 0700, 0701, 0702, 07020, 07021, 07022, 07023, 0703, 07030, 07031, 07032, 07033, 0704, 07041, 07042, } \\
\text { 07043, 07044, 07049, 0705, 07051, 07052, 07053, 07054, 07059, 0706, 0707, 07070, 07071, 0709, 456, } \\
4560,4561,4562,45620,45621,4563,4564,4565,4566,4568,570,571,5710,5711,5712,5713,5714, \\
57140,57141,57142,57149,5715,5716,5718,5719,572,5720,5721,5722,5723,5724,5728,573,5730, \\
5731,5732,5733,5734,5735,5738,5738,7824,7891,7895,78951,78959,7904,7905,7948, \text { and V427 }\end{array}$ \\
\hline \multirow[t]{2}{*}{ Cancer } & $\begin{array}{l}\text { Oropharyngeal cancers } \\
\text { Diagnosis codes (from index and previous admissions) } \\
\begin{array}{l}140,1400,1401,1403,1404,1405,1406,1408,1409,141,1410,1411,1412,1413,1414,1415,1416, \\
1418,1419,142,1420,1421,1422,1428,1429,143,1430,1431,1438,1439,144,1440,1441,1448, \\
1449,145,1450,1451,1452,1453,1454,1455,1456,1458,1459,146,1460,1461,1462,1463, \\
1464,1465,1466,1467,1468,1469,147,1470,1471,1472,1473,1478,1479,148,1480,1481, \\
1482,1483,1488,1489,149,1490,1491,1498 \text { and } 1499\end{array}\end{array}$ \\
\hline & $\begin{array}{l}\text { Gastrointestinal cancers } \\
\text { Diagnosis codes (from index and previous admissions) } \\
\quad 150,1500,1501,1502,1503,1504,1505,1506,1508,1509,1510,151,1511,15012,1513,1514,1515, \\
\quad 1516,1518,1519,152,1520,1521,1522,1523,1528,1529,153,1530,1531,1532,1533,1534,\end{array}$ \\
\hline
\end{tabular}

(Continued) 
Respiratory tract cancers

Diagnosis codes (from index and previous admissions)

$160,1600,1601,1602,1603,1604,1605,1608,1609,161,1610,1611,1612,1613,1618,1619,162$, $1620,1622,1623,1624,1625,1628,1629,163,1630,1631,1638,1639,164,1640,1461,1462$, $1463,1468,1649,165,1650,1658$ and 1659

Bone and connective tissue cancer

Diagnosis codes (from index and previous admissions)

170, 1700, 1701, 1702, 1703, 1704, 1705, 1706, 1707, 1708, 1709, 171, 1710, 1712, 1713, 1714, 1715, $1716,1717,1718,1719,172,1720,1721,1722,1723,1724,1725,1726,1727,1728,1729,173$, 1730, 17300, 17301, 17302, 17309, 1731, 17310, 17311, 17312, 17319, 1732, 17320, 17321, 17322, 17329, 1733, 17330, 17331, 17332, 17339, 1734, 17340, 17341, 17342, 17349, 1735, 17350, 17351, 17352, 17359, 1736, 17360, 17361, 17362, 17369, 1737, 17370, 17371, 17372, 17379, 1738, 17380, 17381, 17382, 17389, 1739, 17390, 17391, 17392, 17399, 174, 1740, 1741, 1742, 1743, 1744, 1745, $1746,1748,1749,175,1750,1759,176,1760,1761,1762,1763,1764,1765,1768$ and 1769

Genitourinary cancers

Diagnosis codes (from index and previous admissions)

$179,180,1800,1801,1808,1809,181,182,1820,1821,1828,183,1830,1832,1833,1834,1835$, $1838,1839,184,1840,1841,1842,1843,1844,1848,1849,185,186,1860,1869,187,1871,1872$, $1873,1874,1875,1876,1877,1878,1879,188,1880,1881,1882,1883,1884,1885,1886,1887$, $1888,1889,189,1890,1891,1892,1893,1894,1898$ and 1899

Lymphoid cancers

Diagnosis codes (from index and previous admissions)

200, 2000, 20000, 20001, 20002, 20003, 20004, 20005, 20006, 20007, 20008, 2001, 20010, 20011, 20012, 20013, 20014, 20015, 20016, 20017, 20018, 2002, 20020, 20021, 20022, 20023, 20024, 20025, 20026, 20027, 20028, 2003, 20030, 20031, 20032, 20033, 20034, 20035, 20036, 20037, 20038, 2004, 20040, 20041, 20042, 20043, 20044, 20045, 20046, 20047, 20048, 2005, 20050, 20051, 20052, 20053, 20054, 20055, 20056, 20057, 20058, 2006, 20060, 20061, 20062, 20063, 20064, 20065, 20066, 20067, 20068, 2007, 20070, 20071, 20072, 20073, 20074, 20075, 20076, 20076, 20077, 20078, 2008, 20080, 20081, 20082, 20083, 20084, 20085, 20086, 20087, 20088, 201, 2010, 20100, 20101, 20102, 20103, 20104, 20105, 20106, 20107, 20108, 2011, 20110, 20111, 20112, 20113, 20114, 20115, 20116, 20117, 20118, 2012, 20120, 20121, 20122, 20123, 20124, 20125, 20126, 20127, 20128, 2014, 20140, 20141, 20142, 20143, 20144, 20145, 20146, 20147 , 20148, 2015, 20150, 20151, 20152, 20153, 20154, 20155, 20156, 20157, 20158, 2016, 20160, 20161, 20162, 20163, 20164, 20165, 20166, 20167, 20168, 2017, 20170, 20171, 20172, 20173, 20174, 20175, 20176, 20177, 20178, 2019, 20190, 20191, 20192, 20193, 20194, 20195, 20196, 20197, 20198, 202, 2020, 20200, 20201, 20202, 20203, 20204, 20205, 20206, 20207, 20208, 2021, 20210, 20211, 20212, 20213, 20214, 20215, 20216, 20217, 20218, 2022, 20220, 20221, 20222, 20223, 20224, 20225, 20226, 20227, 20228, 2023, 20230, 20231, 20232, 20233, 20234, 20235, 20236, 20237, 20238, 2024, 20240, 20241, 20242, 20243, 20244, 20245, 20246, 20247, 20248, 2025, 20250, 20251, 20252, 20253, 20254, 20255, 20256, 20257, 20258, 2026, 20260, 20261, 20262, 20263, 20264, 20265, 20266, 20267, 20268, 2027, 20270, 20271, 20272, 20273, 20274, 20275, 20276, 20277, 20278, 2028, 20280, 20281, 20282, 20283, 20284, 20285, 20286, 20287, 20288, 2029, 20290, 20291, 20292, 20293, 20294, 20295, 20296, 20297, 20298, 203, 2030, 20300, 20301, 20302, 2031, 20310, 20311, 20312, 2038, 20380, 20381 and 20382

Hematologic cancers

Diagnosis codes (from index and previous admissions)

204, 2040, 20400, 20401, 20402, 2041, 20410, 20411, 20412, 2042, 20420, 20421, 20422, 2048, 20480, 20481, 20482, 2049, 20490, 20491, 20492, 205, 2050, 20500, 20501, 20502, 2051, 20510, 20511, 20512, 2052, 20520, 20521, 20522, 2053, 20530, 20531, 20532, 2058, 20580, 20581, 20582, 2059, 20590, 20591, 20592, 206, 2060, 20600, 20601, 20602, 2061, 20610, 20611, 20612, 2062, 20620, 20621, 20622, 2068, 20680, 20681, 20682, 2069, 20690, 20691, 20692, 207, 2070, 20700, 20701, 20702, 2071, 20710, 20711, 20712, 2072, 20720, 20721, 20722, 2078, 20780, 20781, 20782, 208,

(Continued) 
TABLE E2. Continued

\begin{tabular}{|c|c|}
\hline Definition & ICD-9-CM code \\
\hline & $\begin{array}{l}\text { 2080, 20800, 20801, 20802, 2081, 20810, 20811, 20812, 2082, 20820, 20821, 20822, 2088, 20880, } \\
\text { 20881, 20882, 2089, 20890, 20891, 20892, 209, 2090, 20900, 20901, 20902, 20903, 2091, 20910, } \\
\text { 20911, 20912, 20913, 20914, 20915, 20916, 20917, 2092, 20920, 20921, 20922, 20923, 20924, } \\
\text { 20925, 20926, 20927, 20929, 2093, 20930, 20931, 20932, 20933, 20934, 20935, 20936, 2094, } \\
\text { 20940, 20941, 20942, 20943, 2095, 20950, 20951, 20952, 20953, 20954, 20955, 20956, 20957, } \\
\text { 2096, 20960, 20961, 20962, 20963, 20964, 20965, 20966, 20967, 20969, 2097, 20970, 20971, } \\
\text { 20972, 20973, 20974, 20975 and 20979 }\end{array}$ \\
\hline & Other cancers \\
\hline & Diagnosis codes (from index and previous admissions) \\
\hline & $\begin{array}{l}190,1900,1901,1902,1903,1904,1905,1906,1907,1908,1909,191,1910,1911,1912,1913,1914, \\
1915,1916,1917,1918,1919,192,1920,1921,1922,1923,1928,1929,193,194,1940,1941,1943, \\
1944,1945,1946,1948,195,1950,1951,1952,1953,1954,1955,1958,196,1960,1961,1962, \\
1963,1965,1966,1968,1969,197,1970,1971,1972,1973,1974,1975,1976,1977,1978,198, \\
1980,1981,1982,1983,1984,1985,1986,1987,1988,19881,19882,19889,199,1990,1991 \text {, and } \\
1992\end{array}$ \\
\hline & $\begin{array}{l}\text { V1001, V1002, V1021, V1003, V1004, V1005, V1006, V1007, V1000, V1009, V1011, V1012, V1020, } \\
\text { V1022, V1082, V1083, V103, V1042, V1043, V1040, V1044, V1046, V1047, V1045, V1048, } \\
\text { V1049, V1051, V1052, V1053, V1050, V1059, V1085, V1086, V1087, V1072, V1071, V1079, } \\
\text { V1060, V1061, V1062, V1063, V1069, V1029, V1081, V1084, V1088, V1089, V109, V1090, } \\
\text { V1091, and V711 }\end{array}$ \\
\hline Cerebrovascular disease & Diagnosis codes (from index and previous admissions) \\
\hline & $\begin{array}{l}3623,36230,36231,36232,36233,36234,36235,36236,36237,3466,34660,34661,34662,34663,430, \\
431,432,4320,4321,4329,433,4330,43300,43301,4331,43310,43311,4332,43320,43321,4333, \\
43330,43331,4338,43380,43381,4339,43390,43391,434,4340,43400,43401,4341,43410,43411, \\
4349,43490,43491,435,4350,4351,4352,4353,4358,4359,436,437,4370,4371,4372,4373,4374, \\
4375,4376,4377,99702,4378,4379,438,4380,4381,43810,43811,43812,43813,43814,43819,4382, \\
43820,43821,43822,4383,43830,43831,43832,4384,43840,43841,43842,4385,43850,43851,43852, \\
4386,4387,4388,43881,43882,43883,43884,43885,43889 \text {, and } 4389\end{array}$ \\
\hline Coagulation disorders & Diagnosis codes (from index and previous admissions) \\
\hline & $\begin{array}{l}286,2860,2861,2862,2863,2864,2865,28652,28653,28659,2866,2867,2869,287,2870,2871,2872, \\
2873,28730,28731,28732,28733,28739,2874,2875,2878, \text { and } 2879\end{array}$ \\
\hline Coronary artery bypass grafting & $\begin{array}{l}\text { Diagnosis codes (from index and previous admissions) } \\
\quad 361,3610,3611,3612,3613,3614,3615,3616,3617 \text {, and } 3619\end{array}$ \\
\hline \multicolumn{2}{|l|}{ Causative organisms } \\
\hline Staphylococcus & $\begin{array}{l}\text { Diagnosis codes (from index admissions) } \\
\text { 0381, 03810, 03811, 03812, 03819,0411, 04111, 04112, 04110, and } 04119\end{array}$ \\
\hline Staphylococcus aureus & $\begin{array}{l}\text { Diagnosis codes (from index admissions) } \\
\text { 03811, 03812, 04111, and } 04112\end{array}$ \\
\hline Methicillin resistant & $\begin{array}{l}\text { Diagnosis codes (from index admissions) } \\
\text { 03812, } 04112 \text { (after 2008) } \\
03811 \text { or } 04111 \text { with either V090 or V091 (before 2008) }\end{array}$ \\
\hline Streptococcus & $\begin{array}{l}\text { Diagnosis codes (from index admissions) } \\
\text { 0380, 0382, 0410, 04100, 04101, 04102, 04103, 04104, 04105, 04109, and } 0412\end{array}$ \\
\hline Oral Streptococcus* & $\begin{array}{l}\text { Diagnosis codes (from index admissions) } \\
04100 \text { and } 04109\end{array}$ \\
\hline Gram-negative bacilli & $\begin{array}{l}\text { Diagnosis codes (from index admissions) } \\
\quad 0384,03840,03841,03842,03843,03844,03849,0413,0414,0415,0416,0417 \text {, and } 04185\end{array}$ \\
\hline Fungi & $\begin{array}{l}\text { Diagnosis codes (from index admissions) } \\
\qquad 1125,11281,1160,11504,11514,11594 \text { and } 1173\end{array}$ \\
\hline
\end{tabular}

ICD-9-CM, The International Classification of Diseases, Ninth Revision, Clinical Modification. *Oral streptococcus was identified by exclusion of pneumococcal, beta-hemolytic, Group D streptococcus and enterococcal Streptococcus, assuming to largely encompass oral streptococcus. 
TABLE E3. Patient demographics in propensity score matched cohort

\begin{tabular}{|c|c|c|c|c|}
\hline & $\begin{array}{l}\text { Mitral valve repair } \\
\quad(\mathrm{n}=\mathbf{2 6 6})\end{array}$ & $\begin{array}{l}\text { Mitral valve replacement } \\
\qquad(\mathbf{n}=\mathbf{5 3 2})\end{array}$ & $\begin{array}{l}\text { Standardized } \\
\text { difference, } \%\end{array}$ & $P$ value \\
\hline Age, $y$ & $56.2 \pm 15.5$ & $55.6 \pm 14.6$ & 4.1 & .38 \\
\hline Male & $166(62.4)$ & $319(60.0)$ & 5.0 & .50 \\
\hline \multicolumn{5}{|l|}{ Race } \\
\hline White & $189(71.1)$ & $381(71.6)$ & 1.3 & .87 \\
\hline Black & $22(8.3)$ & $57(10.7)$ & 8.3 & .28 \\
\hline Others & $55(20.7)$ & 94 (17.7) & 7.7 & .30 \\
\hline Residency in California & $142(53.4)$ & $281(52.8)$ & 1.1 & .88 \\
\hline \multicolumn{5}{|l|}{ Comorbidities } \\
\hline Hypertension & $135(50.8)$ & $259(48.7)$ & 4.1 & .58 \\
\hline Diabetes & $28(10.5)$ & $55(10.3)$ & 0.6 & .93 \\
\hline Coronary artery disease & $109(41.0)$ & $228(42.9)$ & 3.8 & .60 \\
\hline Atrial fibrillation & $60(22.6)$ & $121(22.7)$ & 0.5 & .95 \\
\hline Peripheral vascular disease & $28(10.5)$ & $58(10.9)$ & 1.2 & .87 \\
\hline Congestive heart failure & $140(52.6)$ & $260(48.9)$ & 7.5 & .33 \\
\hline Cerebrovascular disease & $61(22.9)$ & $123(23.1)$ & 0.5 & .95 \\
\hline Chronic obstructive pulmonary disease & $41(15.4)$ & $92(17.3)$ & 5.1 & .50 \\
\hline Chronic kidney failure & $60(22.6)$ & $123(23.1)$ & 1.3 & .86 \\
\hline Dialysis dependent & $42(15.8)$ & $82(15.4)$ & 1.0 & .89 \\
\hline Liver disease & $34(12.8)$ & $73(13.7)$ & 2.8 & .71 \\
\hline Cancer & $29(10.9)$ & $45(8.5)$ & 8.3 & .25 \\
\hline Coagulation disorders & $38(14.3)$ & $79(14.8)$ & 1.6 & .83 \\
\hline \multicolumn{5}{|l|}{ Pathogen } \\
\hline Staphylococcus & $70(26.3)$ & $134(25.2)$ & 2.6 & .73 \\
\hline$S$ aureus & $59(22.2)$ & $127(23.9)$ & 4.0 & .59 \\
\hline MRSA & $21(7.9)$ & $36(6.8)$ & 4.3 & .56 \\
\hline Streptococcus & $83(31.2)$ & $162(30.5)$ & 1.6 & .83 \\
\hline Oral streptococcus & $48(18.0)$ & $91(17.1)$ & 2.5 & .74 \\
\hline Gram negative & $<15(5.6)^{*}$ & $20(3.8)$ & 5.6 & .45 \\
\hline Fungus & $<15(5.6)^{*}$ & $<15(2.8)^{*}$ & 0 & 1.00 \\
\hline Concomitant coronary artery bypass graft & $53(19.9)$ & $101(19.0)$ & 2.4 & .75 \\
\hline
\end{tabular}

Values are $\mathrm{n}(\%)$, or mean \pm standard deviation, unless otherwise indicated. MRSA, Methicillin-resistant Staphylococcus aureus. *Small cell sizes (numbers $<15)$ are suppressed based on Data Use Agreement with the Statewide Planning and Research Cooperative System and Office of Statewide Health Planning and Development in California. 
TABLE E4. Risk factors associated with mortality, recurrence of infective endocarditis, and mitral valve reoperation in multivariable regression models

\begin{tabular}{|c|c|c|}
\hline Mortality & HR $(95 \%$ CI $)$ & $P$ value \\
\hline Repair vs replacement & $0.71(0.57-0.88)$ & .002 \\
\hline Age & $1.03(1.02-1.04)$ & $<.001$ \\
\hline Male vs female & $0.86(0.75-0.99)$ & .03 \\
\hline \multicolumn{3}{|l|}{ Race } \\
\hline White & Reference & $<.001$ \\
\hline Black & $1.60(1.30-1.98)$ & \\
\hline Others & $0.97(0.79-1.18)$ & \\
\hline Residency in California & $0.88(0.76-1.02)$ & .09 \\
\hline Admission years & $0.92(0.90-0.94)$ & $<.001$ \\
\hline \multicolumn{3}{|l|}{ Comorbidities } \\
\hline Hypertension & $1.48(1.21-1.82)$ & $<.001$ \\
\hline Diabetes & $1.30(1.07-1.57)$ & .008 \\
\hline Coronary artery disease & $1.12(0.93-1.36)$ & .23 \\
\hline Atrial fibrillation & $0.91(0.77-1.08)$ & .91 \\
\hline Peripheral vascular disease & $1.33(1.04-1.70)$ & .02 \\
\hline Congestive heart failure & $1.11(0.94-1.30)$ & .22 \\
\hline Cerebrovascular disease & $0.95(0.79-1.15)$ & .63 \\
\hline $\begin{array}{l}\text { Chronic obstructive } \\
\text { pulmonary disease }\end{array}$ & $1.28(1.00-1.49)$ & .001 \\
\hline Dialysis dependent & $2.62(2.04-3.37)$ & $<.001$ \\
\hline Liver disease & $1.24(1.00-1.53)$ & .05 \\
\hline Cancer & $1.47(1.18-1.83)$ & $<.001$ \\
\hline Coagulation disorders & $1.54(1.28-1.84)$ & $<.001$ \\
\hline \multicolumn{3}{|l|}{ Pathogen } \\
\hline Staphylococcus & $1.54(1.26-1.89)$ & $<.001$ \\
\hline Streptococcus & Reference & \\
\hline Gram negative & $1.65(1.25-2.17)$ & .004 \\
\hline Fungus & $2.10(0.97-4.59)$ & .06 \\
\hline $\begin{array}{l}\text { Concomitant coronary artery } \\
\text { bypass graft }\end{array}$ & $1.16(0.97-1.39)$ & .12 \\
\hline \multicolumn{3}{|l|}{ Recurrence } \\
\hline \multicolumn{3}{|l|}{ Repair vs replacement* } \\
\hline At $1 \mathrm{y}$ & $0.70(0.43-1.16)$ & .17 \\
\hline At $2 \mathrm{y}$ & $0.47(0.26-0.83)$ & .009 \\
\hline At $5 \mathrm{y}$ & $0.14(0.03-0.62)$ & .01 \\
\hline Age & $1.01(1.00-1.03)$ & .03 \\
\hline Male vs female & $0.93(0.68-1.28)$ & .66 \\
\hline Race & & .003 \\
\hline White & Reference & \\
\hline Black & $2.06(1.30-3.27)$ & \\
\hline Others & $1.18(0.77-1.82)$ & \\
\hline Residency in California & $1.21(0.89-1.64)$ & .23 \\
\hline Admission years & $0.99(0.94-1.04)$ & .55 \\
\hline \multicolumn{3}{|l|}{ Comorbidities } \\
\hline Dialysis dependent & $3.56(2.43-5.22)$ & $<.001$ \\
\hline
\end{tabular}

TABLE E4. Continued

\begin{tabular}{llc}
\hline \multicolumn{1}{c}{ Recurrence } & & \\
\hline Peripheral vascular disease & $1.57(0.98-2.50)$ & .06 \\
Liver disease & $1.55(1.08-2.22)$ & .02 \\
Coagulation disorders & $1.57(1.11-2.22)$ & .01 \\
\hline \multicolumn{1}{c}{ Reoperation } & & \\
\hline Repair vs replacement* & $1.98(1.28-3.05)$ & .002 \\
At 1 y & $1.41(0.90-2.21)$ & .14 \\
At 2 y & $0.51(0.21-1.24)$ & .14 \\
At 5 y & $0.99(0.98-1.00)$ & .07 \\
Age & $1.06(0.73-1.53)$ & .77 \\
Male vs female & & \\
Race & Reference & 0.20 \\
White & $1.56(0.90-2.70)$ & \\
Black & $1.26(0.85-1.86)$ & \\
Others & $0.77(0.53-1.10)$ & .15 \\
Residency in California & $0.95(0.90-1.00)$ & .04 \\
Admission years & & \\
Comorbidities & $0.63(0.38-1.04)$ & .07 \\
Atrial fibrillation & $2.83(1.78-4.51)$ & $<.001$ \\
Dialysis dependent & $1.89(1.15-3.13)$ & .01 \\
Liver disease & $1.58(0.84-3.00)$ & .16 \\
Cancer & $0.62(0.37-1.05)$ & .08 \\
\hline Concomitant coronary artery bypass graft & & \\
\hline
\end{tabular}

HR, Hazard ratio; $C I$, confidence interval. *Proportional hazard assumption was violated and hazard ratio of recurrence was calculated at different time points. 
TABLE E5. Hazard ratio of each endpoint comparing repair with replacement

\begin{tabular}{|c|c|c|c|c|c|c|c|c|}
\hline & $\begin{array}{l}\text { Multivariable } \\
\text { Cox regression }\end{array}$ & $\begin{array}{c}P \\
\text { value }\end{array}$ & $\begin{array}{l}\text { Propensity } \\
\text { adjustment }\end{array}$ & $\begin{array}{c}P \\
\text { value }\end{array}$ & $\begin{array}{c}\text { Inverse } \\
\text { probability } \\
\text { weighting }\end{array}$ & $\begin{array}{c}P \\
\text { value }\end{array}$ & $\begin{array}{l}\text { Propensity } \\
\text { matching }\end{array}$ & $\begin{array}{c}P \\
\text { value }\end{array}$ \\
\hline Number of patients & $\begin{aligned} \text { Repair, } \mathbf{n} & =367 \\
\text { Replace, } \mathbf{n} & =1603\end{aligned}$ & & $\begin{aligned} \text { Repair, } \mathbf{n} & =367 \\
\text { Replace, } \mathbf{n} & =1603\end{aligned}$ & & $\begin{aligned} \text { Repair, } \mathbf{n} & =367 \\
\text { Replace, } \mathbf{n} & =1603\end{aligned}$ & & $\begin{array}{l}\text { Repair, } n=266 \\
\text { Replace, } n=532\end{array}$ & \\
\hline Mortality & $0.70(0.57-0.87)$ & .002 & $0.75(0.60-0.94)$ & .01 & $0.64(0.59-0.70)$ & $<.001$ & $0.80(0.63-1.03)$ & .08 \\
\hline \multicolumn{9}{|l|}{ Recurrence } \\
\hline $1 \mathrm{y}$ & $0.70(0.43-1.16)$ & .17 & $0.68(0.39-1.18)$ & .17 & $0.74(0.60-0.91)$ & .004 & $0.52(0.26-1.01)$ & .06 \\
\hline $2 \mathrm{y}$ & $0.46(0.26-0.83)$ & .01 & $0.46(0.34-0.89)$ & .02 & $0.54(0.42-0.69)$ & $<.001$ & $0.34(0.16-0.72)$ & .005 \\
\hline $5 y$ & $0.13(0.03-0.61)$ & .01 & $0.14(0.03-0.73)$ & .02 & $0.21(0.12-0.38)$ & $<.001$ & $0.10(0.02-0.54)$ & .007 \\
\hline \multicolumn{9}{|l|}{ Reoperation } \\
\hline $1 \mathrm{y}$ & $2.03(1.31-3.15)$ & .002 & $2.13(1.32-3.45)$ & .002 & $1.96(1.65-2.32)$ & $<.001$ & $2.05(1.15-3.68)$ & .02 \\
\hline $2 y$ & $1.44(0.91-2.27)$ & .12 & $1.55(0.97-2.47)$ & .07 & $1.35(1.12-1.62)$ & .001 & $1.48(0.88-2.50)$ & .14 \\
\hline $5 \mathrm{y}$ & $0.52(0.21-1.26)$ & .15 & $0.59(0.26-1.31)$ & .19 & $0.44(0.30-0.65)$ & $<.001$ & $0.56(0.25-1.26)$ & .16 \\
\hline
\end{tabular}

